\title{
A RANDOMISED, DOUBLE-BLIND, PLACEBO-CONTROLLED TRIAL COMPARING DEXMEDETOMIDINE AND CLONIDINE AS AN ADJUVANT TO INTRATHECAL ROPIVACAINE IN LOWER LIMB SURGERY
}

\author{
${ }_{1}^{1}$ Postgraduate Student, Department of Anaesthesia, KIMS. \\ 2Postgraduate Student, Department of Anaesthesia, KIMS. \\ 3 Postgraduate Student, Department of Anaesthesia, KIMS. \\ ${ }^{4}$ Postgraduate Student, Department of Anaesthesia, KIMS. \\ 5 Postgraduate Student, Department of Anaesthesia, KIMS. \\ ${ }^{6}$ Postgraduate Student, Department of Anaesthesia, KIMS.
}

Tushar B. Munnoli1, Gagandeep Singh², Bilal Mohammad ${ }^{3}$, Indrajit Gupta ${ }^{4}$, Juberahmad Attar ${ }^{5}$, Naveen Kumar Naveen 6

\section{ABSTRACT}

\section{BACKGROUND}

Various adjuvants are being used with local anaesthetics for prolongation of intraoperative and postoperative analgesia. This study was taken up to compare the duration of postoperative analgesia, extent of motor and sensory block, adverse effects along with the haemodynamic changes between ropivacaine alone, ropivacaine with clonidine and ropivacaine with dexmedetomidine.

\section{MATERIALS AND METHODS}

75 adult patients of both sexes undergoing lower limb surgeries under spinal anaesthesia patients of ASA grade I or II, ages between 20 - 50 years, were enrolled in the study. Patients were randomly allocated to three equal groups, Group R received $2.5 \mathrm{~mL}$ of $0.75 \%$ hyperbaric ropivacaine with normal saline as a placebo, group D received Ropivacaine with $3 \mu \mathrm{g}$ of dexmedetomidine and Group $\mathrm{C}$ received Ropivacaine with $30 \mu \mathrm{g}$ of clonidine. All solutions were made up to $3 \mathrm{~mL}$ with addition of normal saline and injected at L3 L4 using a 25-G spinal needle. The onset and duration of sensory and motor blockade, time to reach peak sensory and motor level and the sensory and motor regression times were recorded. Haemodynamic changes and time to use first rescue analgesia, Inj. tramadol hydrochloride $50 \mathrm{mg}$ IV, were also recorded. In Post Anaesthesia Care Unit (PACU), pain scores were recorded using Visual Analogue Scale (VAS) for first 24 hours postoperatively. Descriptive statistics was used for describing frequencies, mean and standard deviation. Analysis of Variance (ANOVA) test was used to compare the quantitative variables in between the three groups, which were independent of each other. Chi square test was used to compare categorical variables. All the data was analysed using SPSS vs. 22. P value $<0.05$ was considered statistically significant.

\section{RESULTS}

There was no significant difference in patient's demographics or duration of surgery in the time of onset of sensory block, but motor block was early in Group D and Group C as compared to Group R. Duration of sensory and motor blockade was prolonged in Groups $\mathrm{C}$ and D compared with Group R. The mean regression time to S1 segment was $298.6 \pm 51$ mins. in Group D, 268.6 \pm 26.4 mins. in Group $\mathrm{C}$ and $199.8 \pm 32.9$ mins. in Group R. The regression of motor block to Bromage zero was $249 \pm 38.40$ mins. in Group D, $229 \pm 42.57$ mins. in Group C and $174 \pm 28.8$ mins. in Group R. The time to analgesia was significantly prolonged in Group D compared with Group $\mathrm{C}$, the latter being longer than Group R.

\section{CONCLUSION}

Intrathecal dexmedetomidine is associated with prolonged motor and sensory block, haemodynamic stability and reduced demand of rescue analgesics in $24 \mathrm{hrs}$. as compared to clonidine or Ropivacaine alone.

\section{KEYWORDS}

Hyperbaric Ropivacaine, Dexmedetomidine, Clonidine, Intrathecal.

HOW TO CITE THIS ARTICLE: Munnoli TB, Singh G, Mohammad B, et al. A randomised, double-blind, placebo-controlled trial comparing dexmedetomidine and clonidine as an adjuvant to intrathecal ropivacaine in lower limb surgery. J. Evolution Med. Dent. Sci. 2016;5(90):6680-6684, DOI: 10.14260/jemds/2016/1511

\section{BACKGROUND}

Subarachnoid blockade is the most commonly used regional anaesthetic technique for lower limb surgery. Bupivacaine is a widely used amide local anaesthetic. Its long duration of action and tendency to provide more sensory than motor block has

Financial or Other, Competing Interest: None.

Submission 05-10-2016, Peer Review 29-10-2016,

Acceptance 04-11-2016, Published 09-11-2016.

Corresponding Author:

Dr. Tushar B. Munnoli,

Sona Clinic, Kudachi-591311,

Belgaum, Karnataka.

E-mail: tusharmunnoli@gmail.com

DOI: $10.14260 /$ jemds/2016/1511 made it a popular drug for providing prolonged analgesia. However, the main disadvantage of bupivacaine is its cardiotoxic effects.[1]

On the other hand, Ropivacaine is a long-acting amide local anaesthetic structurally related to bupivacaine. Ropivacaine has consistently demonstrated a higher safety profile than Bupivacaine with reduced Central Nervous System (CNS) toxic and cardiotoxic potential together with wide clinical utility at different doses and for a wide range of indications. ${ }^{[2,3]}$

Various adjuncts opioids, alpha agonists and midazolam are being used with local anaesthetics for prolongation of intraoperative and postoperative analgesia. However, their use is thwarted either due to the adverse effects of adjuvants or unreliable postoperative analgesia.[4] 
The concept of using adjuvants with local anaesthetics has progressed through the practice of administering opioids such as morphine, fentanyl, sufentanil and alfentanil; $\alpha_{2}$ agonists such as clonidine; and a more selective $\alpha_{2}$ agonist, dexmedetomidine. $\alpha_{2}$ agonists do not have side effects such as nausea, vomiting, urinary retention, pruritus or respiratory depression, which are all commonly associated with opioids.[5,6]

Most of the clinical studies about the intrathecal $\alpha_{2}$ adrenergic agonist are related to clonidine, acts as an analgesic, a sedative and as a sympatholytic with potent antinociceptive properties.[7] Dexmedetomidine, a highly selective $\alpha_{2}$ adrenergic agonist has evolved as a panacea for various applications and procedures in the perioperative and critical care settings.[8] It is also emerging as a valuable adjunct to regional anaesthesia and analgesia, where gradually evolving studies can build the evidence for its safe use in central neuraxial blocks.[9,10]

This study was taken up to compare the duration of postoperative analgesia, extent of motor and sensory block, adverse effects along with the haemodynamic changes between ropivacaine alone, ropivacaine with clonidine and ropivacaine with dexmedetomidine.

\section{MATERIALS AND METHODS}

After obtaining Institutional Ethical Committee approval and written informed consent, 75 adult patients of the American Society of Anaesthesiologists (ASA) grade I and II, aged 18 - 60 years of both sexes, scheduled to undergo elective lower limb surgeries under spinal anaesthesia were included in this randomised, prospective, double-blinded, placebo controlled trial study. Patients with contraindication to regional anaesthesia, history of significant coexisting diseases like ischaemic heart disease, hypertension, impaired renal functions, rheumatoid arthritis and severe liver disease, body weight more than $120 \mathrm{~kg}$, height less than $140 \mathrm{~cm}$, patient on adrenergic receptor agonist or antagonist therapy with known hypersensitivity to local anaesthetic, drugs, pregnant patients, chronic alcoholics and malnourished patients were excluded from the study.

Simple randomisation was done with computer generated random number sequence. Subjects were randomised with a 1:1:1 allocation ratio. The allocated interventions were written on paper slips, placed in serial-numbered, opaque envelopes and sealed. As consecutive eligible subjects got enrolled, the envelopes were serially opened and the allocated intervention was implemented. Group $\mathrm{R}$ received subarachnoid block with injection hyperbaric ropivacaine $(0.75 \%) 2.5 \mathrm{~mL}$ with normal saline as a placebo to make $3 \mathrm{~mL}$. In Group $\mathrm{C}$, the patients received hyperbaric ropivacaine $(0.75 \%) 2.5 \mathrm{~mL}$ with $30 \mu \mathrm{g}(0.2 \mathrm{~mL})$ clonidine and the total volume of the drug was made $3 \mathrm{~mL}$ by adding $0.3 \mathrm{~mL}$ of normal saline. In Group D, the patients received subarachnoid block with injection hyperbaric ropivacaine $(0.75 \%) 2.5 \mathrm{~mL}$ with 3 $\mu \mathrm{g}$ dexmedetomidine. Normal saline was added to $1 \mathrm{~mL}(100$ $\mu \mathrm{g} / \mathrm{mL})$ of dexmedetomidine to make it $10 \mathrm{~mL}(10 \mu \mathrm{g} / \mathrm{mL})$. From this, $0.3 \mathrm{~mL}(3 \mu \mathrm{g})$ of solution was taken with $1 \mathrm{~mL}$ tuberculin syringe with $0.01 \mathrm{~mL}$ marking for intrathecal use. One anaesthesiologist prepared the intrathecal drugs just prior to positioning the patient for spinal anaesthesia. Patient and the anaesthesiologist who attended patient intraoperatively and collected data in the postoperative period were blinded to the study drug.

Group R - Intrathecal (I/T) 0.75\%, Ropivacaine $2.5 \mathrm{~mL}$. + Preservative free normal saline $(0.5 \mathrm{~mL})$.

Group C - (I/T) $0.75 \%$ Ropivacaine $2.5 \mathrm{~mL}+$ Clonidine $30 \mu \mathrm{g}$ $(0.2 \mathrm{~mL})$.

+ Preservative free normal saline $(0.3 \mathrm{~mL})$.

Group D - (I/T) $0.75 \%$ Ropivacaine $2.5 \quad \mathrm{~mL}+$ Dexmedetomidine $3 \mu \mathrm{g}(0.3 \mathrm{~mL})$.

+ Preservative free normal saline $(0.2 \mathrm{~mL})$.

After pre-anaesthetic evaluation, all the patients received alprazolam $0.5 \mathrm{mg}$ and ranitidine $150 \mathrm{mg}$ orally as premedication on the night before surgery and were familiarised with Visual Analogue Scale (VAS) and its use for measuring the postoperative pain and were advised fasting for $6 \mathrm{hrs}$.

On arrival in the operation room, they were preloaded with Ringer's Lactate (RL) solution at $15 \mathrm{~mL} / \mathrm{kg}$ body weight about 15 mins. before the intrathecal drug administration and monitored with pulse oximetry $\left(\mathrm{SpO}_{2}\right)$, Non-Invasive Blood Pressure (NIBP) and electrocardiogram (ECG).

Under aseptic precautions, lumbar puncture was performed at $\mathrm{L}_{3-4}$ intervertebral space using midline approach with a 25-G Quincke spinal needle in the lateral decubitus position and either of the study drugs was administered intrathecally using the randomisation table. The study solution was prepared by a colleague not involved in the study to achieve double blinding.

The time to reach T10 dermatome (onset time), the maximum sensory level achieved, time for two segment and S1 segment regression (the duration of sensory block) were recorded. The motor block was assessed according to the modified Bromage scale $(0-3)$, for onset (Time to reach maximum Bromage level) and duration (Time to Bromage 0 regression). In the intraoperative period, vital parameters ( $\mathrm{HR}, \mathrm{MBP}$ and $\mathrm{SpO}_{2}$ ) were recorded after the block every 3 minutes for half an hour, then every 15 minutes up to 3 hours. On achieving T10 sensory blockade level, surgery was allowed. All episodes of pulse rate and blood pressure variations of more than $20 \%$ of baseline were noted in all groups. Hypotension was treated with ephedrine $6 \mathrm{mg}$ bolus and bradycardia was treated with IV atropine. The sensory and motor blockade were assessed intraoperatively. The onset and duration of sensory block, highest level of sensory block, time to reach the highest dermatomal level of sensory block, motor block onset, time to complete motor block recovery and duration of effective analgesia were recorded. All durations were calculated in relation to the time of subarachnoid block. In Post-Anaesthesia Care Unit (PACU), pain scores were recorded using Visual Analogue Scale (VAS) by nursing staff that were unaware of the group assignment at 1, 4, 8, 12 and 24 hours postoperatively. Duration of pain relief (Effective analgesia) was defined as the time from spinal injection to the first request for rescue analgesics or VAS was $>4$.

Postoperative analgesic rescue was provided by Inj. Tramadol hydrochloride $50 \mathrm{mg}$ IV. The time to request rescue analgesia (the duration of analgesia) was noted. This was taken as the time of wearing off analgesia. Patients discharged from PACU after sensory regression to S1 dermatome and Bromage score reached to zero. Side-effects such as nausea, 
vomiting, bradycardia, hypotension, respiratory depression ( RR < 8/min) and pruritus were noted and treated accordingly.

Hypotension, defined as a fall in systolic blood pressure (SBP) of $>20 \%$ from the baseline was treated with rapid infusion of $500 \mathrm{~mL}$ of $\mathrm{RL}$ and Inj. ephedrine $6 \mathrm{mg}$ bolus Intravenously (IV) and bradycardia defined as HR $<50$ beats per minute (bpm) were treated with Inj. Atropine sulfate 0.6 mg IV.

\section{Statistical Analysis}

We took a convenient sample size of 75 patients, as it was a pilot study. Descriptive statistics was used for describing frequencies, mean and standard deviation. Analysis of Variance (ANOVA) test was used to compare the quantitative variables in between the three groups, which were independent of each other. Chi square test was used to compare categorical variables. All the data was analysed using SPSS vs. 22.0. P value $<0.05$ was considered statistically significant.

\section{RESULTS}

All patients $(n=75)$ completed the study; ninety eight patients posted for lower limb surgeries were enrolled for the study. Eleven patients refused to participate in the study and twelve patients were found to be on beta blockers, anticoagulation drugs and had uncontrolled diabetes mellitus. The remaining 75 patients fulfilling the inclusion criteria were randomly assigned to one of the three groups.

\begin{tabular}{|c|c|c|c|}
\hline Variable & $\begin{array}{c}\text { Group R } \\
\text { (Mean } \pm \text { SD) }\end{array}$ & $\begin{array}{c}\text { Group C } \\
\text { (Mean } \pm \text { SD) }\end{array}$ & $\begin{array}{c}\text { Group D } \\
\text { (Mean } \pm \text { SD) }\end{array}$ \\
\hline Age (Years) & $34 \pm 8.8$ & $32 \pm 8.8$ & $34 \pm 6.8$ \\
\hline Sex (Male) & 17 & 19 & 16 \\
\hline ASA 1:2 & $13: 12$ & $12: 13$ & $11: 14$ \\
\hline Height (cm) & $162 \pm 4.1$ & $164 \pm 8.5$ & $164 \pm 7.6$ \\
\hline Weight (kg) & $59 \pm 6.3$ & $58 \pm 7.4$ & $58 \pm 9.4$ \\
\hline $\begin{array}{c}\text { Duration of } \\
\text { Surgery (min.) }\end{array}$ & $93 \pm 26.3$ & $83.2 \pm 23.6$ & $95.6 \pm 25.9$ \\
\hline \multicolumn{4}{|c|}{ Table 1. Patient's Demographics } \\
\hline
\end{tabular}

The groups were comparable with respect to age, sex and ASA physical status. There was no significant difference in the duration of surgery (Table 1). The numbers of patients under each type of surgery performed on the lower limb were similar amongst the groups, thereby keeping the comparison unbiased.

\begin{tabular}{|c|c|c|c|c|}
\hline Variable & $\begin{array}{c}\text { Group R } \\
\text { (Mean } \pm \text { SD) }\end{array}$ & $\begin{array}{c}\text { Group C } \\
\text { (Mean } \pm \text { SD) }\end{array}$ & $\begin{array}{c}\text { Group D } \\
\text { (Mean } \pm \text { SD) }\end{array}$ & $\begin{array}{c}\text { P } \\
\text { value }\end{array}$ \\
\hline $\begin{array}{c}\text { Time of onset of } \\
\text { motor block } \\
\text { (Bromage Score } \\
3 \text { ) *min) }\end{array}$ & $15 \pm 3.4$ & $9 \pm 1.8$ & $9 \pm 1.7$ & 0.014 \\
\hline $\begin{array}{c}\text { Time of onset of } \\
\text { Sensory Block } \\
\text { (up to T10) } \\
\text { (min) }\end{array}$ & $6.00 \pm 1.28$ & $6.00 \pm 1.258$ & $6.32 \pm 1.474$ & 0.12 \\
\hline $\begin{array}{c}\text { Maximum } \\
\text { Height of } \\
\text { Sensory block } \\
\text { (Thoracic level) }\end{array}$ & $6 \pm 1.52$ & $6 \pm 1.47$ & $6 \pm 1.155$ & 0.089 \\
\hline
\end{tabular}

\begin{tabular}{|c|l|l|l|l|}
\hline $\begin{array}{c}\text { Time to reach } \\
\text { Maximum } \\
\text { Height of } \\
\begin{array}{c}\text { Sensory Block } \\
\text { (min) }\end{array}\end{array}$ & $16 \pm 3.85$ & $14 \pm 4.11$ & $17 \pm 4.51$ & 0.15 \\
\hline $\begin{array}{c}\text { Duration of } \\
\text { Motor Block } \\
\text { (Regression to } \\
\text { Bromage } \\
\text { score zero) }\end{array}$ & $174 \pm 28.8$ & $229 \pm 42.57$ & $249 \pm 38.40$ & 0.001 \\
\hline $\begin{array}{c}\text { Duration of } \\
\text { Sensory Block } \\
\text { (Two Segment } \\
\text { Regression } \\
\text { Time) (min) } \pm\end{array}$ & $100.4 \pm 29.2$ & $121.00 \pm 30.9$ & $139.8 \pm 30.9$ & 0.003 \\
\hline $\begin{array}{c}\text { Regression to S1 } \\
\text { Dermatome } \\
\text { (min) } \neq\end{array}$ & $199.8 \pm 32.9$ & $268.6 \pm 26.4$ & $298.6 \pm 51$ & 0.001 \\
\hline $\begin{array}{c}\text { Duration of } \\
\text { Analgesic } \\
\text { Effect of Spinal } \\
\text { Anaesthesia }\end{array}$ & $204 \pm 16.9$ & $301 \pm 51.5$ & $316 \pm 55.9$ & 0.001 \\
\hline \multicolumn{2}{|c|}{ Table 2. Characteristics of Spinal Block } \\
\hline \multicolumn{2}{|c|}{} & & & \\
\hline
\end{tabular}

*Intergroup comparison $\mathrm{R}$ to $\mathrm{C}$ and $\mathrm{R}$ to $\mathrm{D}$; $\mathrm{P}$ value was significant $(<0.001)$, whereas $C$ to $D$ was not significant $(p>$ 0.05).

\pm Intergroup comparison $\mathrm{R}$ to $\mathrm{D}, \mathrm{R}$ to $\mathrm{C}$ and $\mathrm{C}$ to $\mathrm{D}$ was significant $(\mathrm{p}<0.05)$.

\#Intergroup comparison $\mathrm{R}$ to $\mathrm{C}$ and $\mathrm{R}$ to $\mathrm{D}$ was significant $(\mathrm{p}<$ $0.05)$, whereas $C$ to $D$ was not significant ( $p>0.05$ ).

The time of onset of sensory block (to reach T10) was statistically insignificant in all the three groups. T10 sensory level was achieved in all patients. In Groups R, $\mathrm{C}$ and D sensory block to a level of T10 reached at $6 \pm 1.28,6.00 \pm 1.25$ and $6.32 \pm 1.4$ mins. respectively after the injection (Statistically insignificant).

However, there were patients with level progressing further to the highest sensory level of T4. T6 was the mean level of sensory block attained at $16 \pm 3.8,14 \pm 4.18,17 \pm 4.52$ mins. after injection in 40, 60 and $68 \%$ patients in Group R, C and $\mathrm{D}$ respectively.

Onset of motor block (Time to achieve Bromage score 3) was statistically significant between Group R and C as well as between $\mathrm{R}$ and $\mathrm{D}$, but not between $\mathrm{C}$ and $\mathrm{D}$ (Table 2 ).

Difference between duration of sensory and motor block was statistically significant in the three groups (Table 2).

There was statistically significant difference in time of first rescue dose requested by patient, it was $204 \pm 16.9$ mins. in Group R, 301 \pm 51.5 mins. in Group C and 316 \pm 55.9 mins. in Group D with $\mathrm{p}$ value $<0.05$.

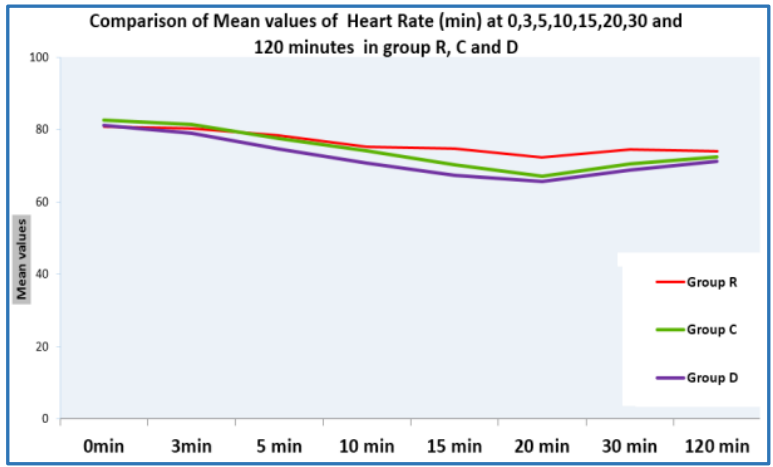

Figure 1. Trend of Heart Rate 


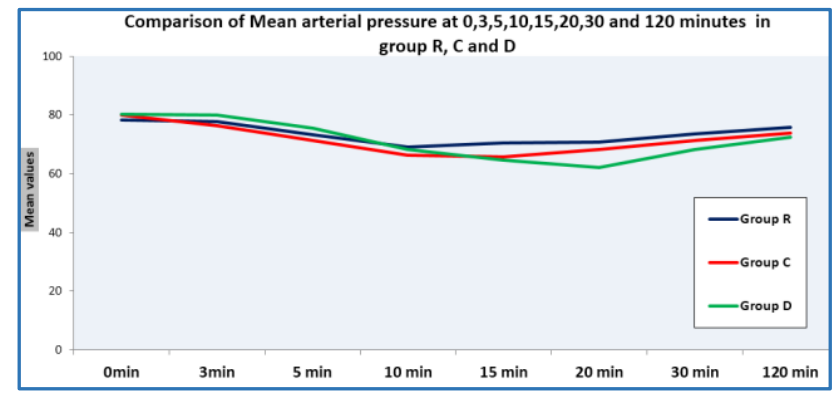

Figure 2. Trend of Mean BP

The mean values of systolic, diastolic, Mean Arterial Pressure (MAP) and Heart Rate (HR) were comparable between the three groups throughout the intraoperative and postoperative periods (Figure. 1 and 2). All patients had $\mathrm{SpO}_{2}$ greater than $95 \%$ at all the times and did not require additional oxygen in PACU.

Two and four patients in Groups $\mathrm{R}$ and $\mathrm{C}$ respectively and one patient in Group D received one dose of Ephedrine. Three patients in Group D required atropine.

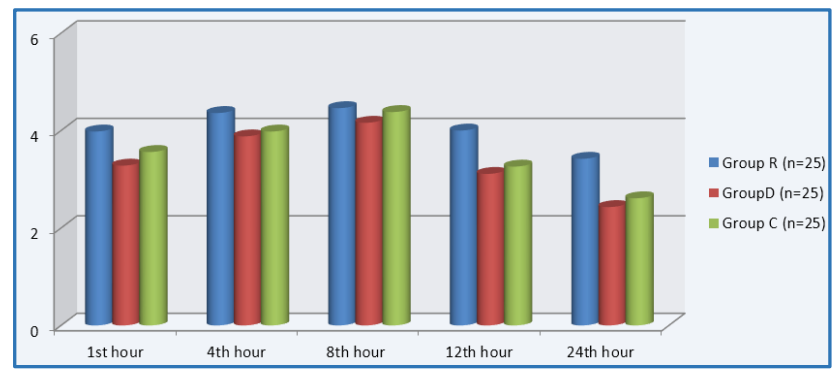

Figure 3. Graph of VAS Score

The VAS intraoperatively was less than 3 in all groups. However, the VAS score was higher in Group $\mathrm{R}$ in postoperative period. The requirement of analgesic top-up in postoperative period was more and earlier in Group $\mathrm{R}$ as compared to Group C and Group D. But on comparing the Group C and Group D, the VAS score was less in Group D and the analgesic effect of subarachnoid block remained longer in Group D.

\begin{tabular}{|c|c|c|c|}
\hline $\begin{array}{c}\text { Side } \\
\text { Effect }\end{array}$ & $\begin{array}{c}\text { Group R } \\
\text { n (\%) }\end{array}$ & $\begin{array}{c}\text { Group C } \\
\text { n (\%) }\end{array}$ & $\begin{array}{c}\text { Group D } \\
\text { n (\%) }\end{array}$ \\
\hline Hypotension & $2(8)$ & $4(16)$ & $1(4)$ \\
\hline Bradycardia & 0 & $1(4)$ & $3(12)$ \\
\hline Shivering & $4(16)$ & $1(4)$ & 0 \\
\hline $\begin{array}{c}\text { Nausea/ } \\
\text { Vomiting }\end{array}$ & $3(12)$ & 0 & $2(8)$ \\
\hline \multicolumn{4}{|c|}{ Table 3. Description of Side Effects } \\
\hline
\end{tabular}

Intra-operative or post-operative nausea or vomiting occurred in 3 patients in Group R and 2 patients in Group D. Incidence of Hypotension was more in Group C.

\section{DISCUSSION}

Asano et al[11] showed that binding affinity to spinal $\alpha_{2}$ receptors of dexmedetomidine when compared with clonidine is approximately 1:10. In our study, we selected $10 \times$ the dose of dexmedetomidine as clonidine, i.e. $30 \mu \mathrm{g}$.
Prolongation of spinal anaesthesia after IV dexmedetomidine is by its supraspinal action at locus coeruleus and dorsal raphe nucleus. There are three subtypes of $\alpha 2$ receptors: A, B and C. Dexmedetomidine is a more selective $\alpha 2-\mathrm{A}$ receptor agonist than clonidine with more sedative and analgesic effects. Activation of presynaptic $\alpha 2-\mathrm{A}$ receptor at locus coeruleus decreases norepinephrine release and causes sedative and hypnotic effects, whereas its effect on descending medullo-spinal noradrenergic pathway results in analgesia by terminating pain signal propagation. At substantia gelatinosa of the spinal cord, it decreases firing in nociceptive neurons and release of substance $P$, thus producing analgesia. So, dexmedetomidine has a role in modulating pain and inhibiting the transmission and perception of pain. Activation of post-synaptic $\alpha 2$-A receptors in CNS results in hypotension and bradycardia by decreasing the sympathetic activity. Activation of post-synaptic $\alpha 2-C$ receptors in CNS results in anxiolysis, whereas activation of post-synaptic $\alpha 2$-B receptors in peripheral vasculature results in transient hypertension.

In our study it was observed that dexmedetomidine $3 \mu \mathrm{g}$ supplemented to intrathecal ropivacaine significantly prolonged the duration of postoperative analgesia compared with the addition of clonidine $30 \mu \mathrm{g}$ and ropivacaine alone. Both dexmedetomidine and clonidine prolonged both sensory and motor blockade compared to Ropivacaine alone and reduced the need of rescue analgesia for the first 24 postoperative hours. Many studies are published about intrathecal use of clonidine,[12] but literature is scarce about intrathecal dexmedetomidine as an adjuvant to spinal local anaesthetics. Intrathecal $\alpha 2$-adrenoceptor agonists produce analgesia by binding and depressing the release of presynaptic C-fibre neurotransmitters and also by hyperpolarisation of post-synaptic dorsal horn neurons.[13,14] This anti-nociceptive effect may explain the prolongation of the sensory block, while prolongation of motor block may be due to the binding of $\alpha 2$-adrenoceptor agonists to motor neurons in the dorsal horn.[15]

Bradycardia and hypotension are most important side effect of intrathecal $\alpha$-adrenergic receptor agonists. ${ }^{[16]}$ The use of dexmedetomidine was associated with a decrease in HR and blood pressure in a study by Al-Ghanem et al.[17] In the present study, bradycardia was seen in 1 case and 3 cases of hypotension were observed. This could be due to the combination of $\alpha_{2}$ agonists with ropivacaine, even though ropivacaine has been shown to be a better drug in terms of cardiovascular and haemodynamic control.[18,19] In our study these side effects were not significant, may be because of small dose of intrathecal dexmedetomidine and clonidine used in our study, which was supported by the findings of various studies.[17]

\section{Limitations}

This study adds to the current knowledge on dexmedetomidine, but the results should be considered taking into consideration the various limitations. As all patients were either ASA physical status I or II, so results cannot be generalised to ASA physical status III and IV patients. Our patients were young and otherwise healthy ones, free of significant comorbidities that might have exaggerated the cardiovascular side effects of intrathecal clonidine or dexmedetomidine. Hence, further studies that compare the 
effect of intrathecal clonidine and dexmedetomidine on the spinal ropivacaine with large sample size are needed.

\section{CONCLUSION}

Our study concluded that the supplementation of hyperbaric ropivacaine with low dose of dexmedetomidine in subarachnoid block produces significantly prolonged time to analgesia, an early onset of motor block and a significantly longer sensory and motor block than ropivacaine plus clonidine or ropivacaine alone.

\section{ACKNOWLEDGEMENT}

I acknowledge with thanks the support extended by Dr. Pradeep T. S. for the Statistics and Research Committee, KIMS, Karad.

\section{REFERENCES}

1. Catterall W, Mackie K. Local anesthetics. In: Gilman AG, Hardman JG, Limbird LE, (eds). Goodman and gilman's the pharmacological basis of therapeutics. 10 th edn. USA, McGraw Hill 2001:p 375.

2. Wille M. Intrathecal use of ropivacaine: a review. Acta Anaesthesiol Belg 2004;55(3):251-9.

3. Kuthiala G, Chaudhary G. Ropivacaine: a review of its pharmacology and clinical use. Indian J Anaesth 2011;55(2):104-10.

4. Pitkänen M. Spinal (subarachnoid) blockade. In: Cousin MJ, Bridenbaugh PO, Carr DB, et al. (eds) Neural blockade in clinical anaesthesia and management of pain. $4^{\text {th }}$ edn. Philadelphia: Lippincot Williams and Wilkins 2009:21338.

5. Gutstein HB, Akil H. Opioid analgesics. In: Gilman AG, Hardman JG, Limbird LE. Goodman and gilman's the pharmacological basis of therapeutics. 10th edn. USA, McGraw Hill 2001:595-6.

6. Bajwa SJ, Bajwa SK, Kaur J, et al. Prevention of hypotension and prolongation of postoperative analgesia in emergency cesarean sections: a randomized study with intrathecal clonidine. Int J Crit Illn Inj Sci 2012;2(2):63-9.

7. Elia N, Culebras X, Mazza C, et al. Clonidine as an adjuvant to intrathecal local anesthetics for surgery: systematic review of randomized trials. Reg Anesth Pain Med 2008;33(2):159-67.

8. Mantz J, Josserand J, Hamada S. Dexmedetomidine: new insights. Eur J Anaesthesiol 2011;28(1):3-6.
9. Kanazi GE, Aouad MT, Jabbour-Khoury SI, et al. Effect of low-dose dexmedetomidine or clonidine on the characteristics of bupivacaine spinal block. Acta Anaesthesiol Scand 2006;50(2):222-7.

10. Al-Mustafa MM, Abu-Halaweh SA, Aloweidi AS, et al. Effect of dexmedetomidine added to spinal bupivacaine for urological procedures. Saudi Med J 2009;30(3):365-70.

11. Asano T, Dohi S, Ohta S, et al. Antinociception by epidural and systemic alpha(2)-adrenoreceptor agonists and their binding affinity in rat spinal cord and brain. Anesth Analg 2000;90(2):400-7.

12. De Kock M, Gautier P, Fanard L, et al. Intrathecal ropivacaine and clonidine for ambulatory arthroscopy: a dose-response study. Anesthesiology 2001;94(4):574-8.

13. Lawhead RG, Blaxall HS, Bylund DB. Alpha-2A is the predominant alpha-2 adrenergic receptor subtype in human spinal cord. Anesthesiology 1992;77(5):983-91.

14. Yaksh TL, Jage J, Takano Y. Pharmacokinetics and pharmacodynamics of medullar agents. The spinal actions of a-2 adrenergic agonists as analgesics. Baillière's clinical anaesthesiology 1993;7(3):597-614.

15. Solanki SL, Bharti N, Batra YK, et al. The analgesic effect of intrathecal dexmedetomidine or clonidine, with bupivacaine, in trauma patients undergoing lower limb surgery: $a$ randomised, double-blind study. Anaesth Intensive Care 2013;41(1):51-6.

16. Eisenach JC, De Kock M, Klimscha W. Alpha 2- adrenergic agonists for regional anesthesia. A clinical review of clonidine (1984-1995). Anesthesiology 1996;85(3):65574.

17. Al-Ghanem SM, Massad IM, Al-Mustafa MM, et al. Effect of adding dexmedetomidine versus fentanyl to intrathecal bupivacaine on spinal block characteristics in gynecological procedures: a double blind controlled study. American J Appl Sci 2009;6:882-7.

18. Yamashita A, Matsumoto $M$, Matsumoto S, et al. A comparison of the neurotoxic effects on the spinal cord of tetracaine, lidocaine, bupivacaine, and ropivacaine administered intrathecally in rabbits. Anesth Analg 2003;97(2):512-9.

19. McNamee DA, Convery PN, Milligan KR. Total knee replacement: a comparison of ropivacaine and bupivacaine in combined femoral and sciatic block. Acta Anaesthesiol Scand 2001;45(4):477-81. 